\title{
Produtividade e composição proteica do capim- elefante recebendo adubação orgânica e mineral
}

\author{
Productivity and protein composition of elephant grass \\ receiving organic and mineral fertilizer
}

Guilherme Mendes Machado Franco de Arruda ${ }^{[a]}$, Marco Aurélio Factori ${ }^{[b]}$, Ciniro Costa $a^{[c]}$, Paulo Roberto de Lima Meirelles ${ }^{[c]}$, Marina Gabriela Berchiol da Silva ${ }^{[c]}$, Vania Luzia Fournou de Lima ${ }^{[d]}$,Janaina Conte Hadlich ${ }^{[c]}$, Márcia Pereira da Silva ${ }^{[e]}$

[a] Zootecnista, mestre em Zootecnia pela Universidade Estadual Paulista "Júlio de Mesquita Filho" (UNESP), Botucatu, SP Brasil, e-mail: gui2mfazoo@yahoo.com.br

[b] Zootecnista, doutor em Zootecnia, pós-doutorando do Departamento de Melhoramento e Nutrição Animal da Faculdade de Medicina veterinária e Zootecnia, Universidade Estadual Paulista “Júlio de Mesquita Filho" (UNESP), Botucatu, SP Brasil, e-mail: mafactori@yahoo.com.br

[c] Zootecnistas, doutores em Zootecnia, professores do Departamento de Melhoramento e Nutrição Animal da Faculdade de Medicina Veterinária e Zootecnia, Universidade Estadual Paulista “Júlio de Mesquita Filho" (UNESP), Botucatu, SP - Brasil, e-mail: ciniro@fmvz.unesp.br; paulom@fmvz.unesp.br; gabiberchiol@hotmail.com; jana.hadlich@gmail.com

[d] Zootecnista, mestranda do Programa de Pós-Graduação em Zootecnia da Faculdade de Medicina Veterinária e Zootecnia, Universidade Estadual Paulista "Júlio de Mesquita Filho" (UNESP), Botucatu, SP - Brasil, e-mail: fournou.vania@gmail.com

[e] Graduanda em Zootecnia, Universidade Estadual Paulista "Júlio de Mesquita Filho" (UNESP), Botucatu, SP - Brasil, e-mail: marciaps22@gmail.com

\section{Resumo}

Foi avaliado neste trabalho o efeito do uso da cama de frango em substituição ao adubo químico em pastagem de Pennisetum purpureum cv. Napier sobre a produtividade de massa seca e o teor de proteína bruta desta forragem. A área utilizada foi uma pastagem de P. purpureum cv Napier plantada em linha em solo arenoso. A área utilizada para as parcelas foi de 800 metros quadrados, subdividida em cinco blocos com três parcelas. Os cortes foram efetuados a cada 42 dias, sendo avaliada a área durante um ano. Os tratamentos utilizados foram: T1 - cama de frango na dosagem de 20 toneladas por hectare, aplicada de uma única vez, 30 dias antes do primeiro ciclo de pastejo; T2 - cama de frango na dosagem de 20 toneladas por hectare, dividida em cinco aplicações, respectivamente, nos cinco ciclos de pastejo de verão (quatro toneladas por aplicação); T3 - ureia na dosagem de $150 \mathrm{~kg}$ por hectare. Foram efetuadas separações morfológicas e por estratos (45-100 e >100 cm) durante o período do experimento. 0 delineamento experimental foi em blocos ao acaso (cinco blocos com três parcelas por bloco). Não ocorreram diferenças na produção de massa seca de forragem entre os tratamentos, nas frações resultantes da separação botânica (folha, colmo e material senescente) e nem na estratificação e teor de proteína bruta da forragem. 0 uso da cama de frango 
como adubo orgânico em substituição à ureia é viável em função da obtenção de níveis semelhantes de produtividade e qualidade do capim-elefante.

Palavras-chave: Cama de frango. Fertilizante. Pennisetum purpureum. Ureia.

\section{Abstract}

This work evaluated the productivity of dry matter and crude protein in Pennisetum purpureum cv Napier pasture fertilized with poultry litter to replace chemical fertilizers. The area used was a grazing Pennisetum purpureum cv Napier planted in line on a sandy soil. The area used for the plots was of approximately $800 \mathrm{~m}^{2}$, divided into five blocks with three portions of $6 \times 7 \mathrm{~m}$. Samples were collected every 42 days during one year. The treatments were: T1 - 20 tonnes of poultry litter per hectare applied only once, 30 days before the first grazing cycle (Instruction No. 15 and No. 8 - MAP); T2 - 20 tonnes of poultry litter per hectare divided into 5 applications during summer grazing (4 tons per application); and T3- $70 \mathrm{~kg}$ nitrogen ( $N$ ) per hectare (approximately $150 \mathrm{~kg}$ of urea). Morphological and strata separations were carried out during the experimental period, which was conducted in a completely randomized block design ( 5 blocks of 3 plots per block). Results showed no differences in dry matter production, morphology, strata and crude protein levels among treatments. Therefore, the use of poultry litter as an organic fertilizer in elephant grass pastures is feasible since it generates the same levels of productivity and quality than urea fertilization.

Keywords: Fertilizer. Poultry litter. Pennisetum purpureum. Urea.

\section{Introdução}

Uma vez tendo sido proibido o uso da cama aviária ou cama de frango na alimentação de ruminantes (Instrução Normativa no. 15 de 06/05/2009 e Instrução Normativa no. 8 de 25/03/2004 do Ministério da Agricultura, Pecuária e Abastecimento - MAPA), o seu uso como adubo orgânico tem sido a alternativa adotada por avicultores e produtores de leite e corte, tornando seguro e rentável o destino desse resíduo da criação, além de reduzir o custo de produção devido à substituição do adubo químico na produção de forragem.

No caso de pastagens, o pastejo só é permitido no mínimo 30 dias após sua aplicação no solo (MAPA, 2004), período necessário para que a cama se torne indisponível ao consumo do animal. Segundo Menezes et al. (2004), para diminuir o impacto ao meio ambiente, a cama deve ser aplicada segundo conceitos técnicos, quantificando a sua composição química e as necessidades de nutrientes do solo. 0 produtor que optar por este tipo de fertilização orgânica do solo deve avaliar anualmente o balanço entre os nutrientes, bem como analisar a água de superfície onde a cama é aplicada, pois este é o principal indicativo das perdas de nutrientes, principalmente nitrato ( ${\mathrm{N}-\mathrm{NO}_{3}^{-}}_{3}$ ), por lixiviação.

Todavia, a produtividade do capim está diretamente relacionada com a adubação nitrogenada, a qual é responsável, principalmente, pela produção de folhas. No entanto, para que se tenha produção de massa seca (PMS), os diversos nutrientes devem estar equilibrados na planta em suas devidas porcentagens, a fim de que a produção ocorra. Assim, a ureia (o fertilizante mais utilizado para repor nitrogênio no solo) tem em seu preço um fator desestimulante para os produtores uma vez que, em pastagem, é o único adubo aplicado em algumas situações, considerando solos previamente corrigidos.

Segundo Kiehl (1985), o efeito da matéria orgânica (MO) sobre a produtividade pode ser direto por meio do fornecimento de nutrientes ou pelas modificações das propriedades físicas do solo, melhorando o ambiente radicular e estimulando o desenvolvimento das plantas. No entanto, cabe ressaltar que o uso de adubos orgânicos promove a liberação lenta e gradual de nutrientes com a vantagem de aumentar o teor de MO do solo, solubilizando 
gradativamente macro e micronutrientes para a solução do solo (MENEZES et al., 2004). Tal liberação acontece à medida que o material orgânico vai sendo mineralizado. A quantidade disponível para a planta depende do grau de mineralização, da matéria prima que deu origem ao composto e da quantidade aplicada.

Moraes et al. (2006), estudando potencialidade do uso da cama de frango na recuperação das pastagens degradadas de Brachiaria decumbens, constataram que a cama de frango promoveu as mesmas PMS dos demais fertilizantes. Assim, o objetivo deste estudo foi avaliar o uso da cama de frango em substituição ao adubo químico de ureia na adubação de pastagem de Pennisetum purpureum cv. Napier, sobre a produtividade de massa seca e o teor de proteína bruta da forragem.

\section{Material e métodos}

0 experimento foi realizado em propriedade particular localizada no município de Botucatu (SP), tendo as coordenadas $22^{\circ} 58^{\prime} 24,84^{\prime \prime}$, $48^{\circ} 18^{\prime} 10,41^{\prime \prime} 0$ e altitude média de 570 metros. A área utilizada foi de 800 metros quadrados, onde já se encontrava implantada uma pastagem de $P$. purpureum cv Napier em solo arenoso com declividade de $12 \%$, sendo subdividida em cinco blocos com três parcelas cada de seis por sete metros, com corredores de um metro entre as parcelas, descontando-se as bordaduras. Assim, considerou-se área útil para coleta de cinco por quatro metros. 0 clima da região é o tropical de altitude, com inverno seco e verão quente e chuvoso (LOMBARDI NETO; DRUGOWICH, 1994), com precipitação média de $1300 \mathrm{~mm}$. Os dados de temperatura (temperaturas máxima e mínima verificadas em termômetro digital) e pluviosidade foram coletados na área experimental diariamente. Os dados climáticos foram convertidos e acumulados pelo período de cada corte, pela temperatura em graus dia e pela pluviosidade em milímetros de chuva acumulados.

Para quantificação da reposição de outros nutrientes do solo, foi realizada análise de solo na área. A reposição foi feita de acordo com as exigências da espécie forrageira em estudo. Os teores de V\% foram elevados a 80\%, aplicando-se calcário 60 dias antes do início do experimento. 0 fertilizante fosfatado (superfosfato simples - SS) foi aplicado em cobertura 45 dias antes do início do experimento para elevar o nível para $15 \mathrm{mg} / \mathrm{dm}^{3}$ de solo. As quantidades de potássio foram repostas durante os quatro primeiros ciclos de pastejo, subdivididos em quantidades que não excederam $50 \mathrm{~kg}$ de $\mathrm{K}_{2} \mathrm{O}(100$ a $120 \mathrm{~kg}$ de cloreto de potássio por ciclo), para que o nível de potássio no solo fosse cerca de três mmol/ $\mathrm{dm}^{3}$.

A área foi isolada com cerca de arame liso e utilizada para pastejo com bovinos de corte da raça Nelore. Os animais foram usados apenas como agente de desfolha, não sendo mensurados ganhos de peso destes animais. Os cortes foram efetuados a cada 42 dias no período de 12 meses (agosto de 2010 a setembro de 2011).

Os três tratamentos utilizados foram: T1 - cama de frango na dosagem de $20 \mathrm{t} / \mathrm{ha}(350 \mathrm{~kg} / \mathrm{ha}$ de $\mathrm{N}$ na forma de amônia), aplicada de uma única vez, 30 dias antes do primeiro ciclo de pastejo (Instrução Normativa n․ 15 e n․ 8 - MAPA); T2 - cama de frango na dosagem de $20 \mathrm{t} / \mathrm{ha}$ parcelada em cinco aplicações (cinco ciclos de pastejo de verão com quatro t/ha por aplicação, aproximadamente $70 \mathrm{~kg}$ de $\mathrm{N}$ na forma de amônia); T3 - ureia na dosagem de $70 \mathrm{~kg}$ de nitrogênio $(\mathrm{N})$ por hectare $(150 \mathrm{~kg}$ de ureia aproximadamente) em cinco aplicações (cinco ciclos de pastejo de verão).

Para o cálculo da adubação nitrogenada foi considerado que somente $50 \%$ do nitrogênio total da cama de frango estariam disponíveis no primeiro ano e parte desse nitrogênio na forma de nitrato, que não é a principal forma de absorção pela planta.

No primeiro e segundo ciclos de pastejo, antes da entrada dos animais, foi efetuado o corte de 0,50 metros de altura da forragem contida no interior de uma moldura quadrada de um metro quadrado. Depois de cortada, a forragem era pesada e eram retiradas duas subamostras, sendo uma de $0,150 \mathrm{~kg}$ para determinação da massa seca de forragem após secagem em estufa com ventilação forçada a $60{ }^{\circ} \mathrm{C}$ e a outra de 0,500 kg para separação botânica em lâmina foliar, colmo (colmo + bainha) e material senescente, que após pesados também foram secos em estufa a $60{ }^{\circ} \mathrm{C}$ por 72 horas para determinação da massa seca e produtividade das frações.

Foram avaliadas as produtividades por corte da forragem em todos os ciclos, sendo cinco no período de primavera/verão e três no outono/inverno, 
totalizando oito cortes durante um ano. No terceiro ciclo da primavera/verão foi realizada a mensuração da produtividade de folhas, bem como sua qualidade em dois estratos $(0,45 \mathrm{~m}$ a um metro e acima de um metro), sendo obtida pela multiplicação dos pesos de folhas observados por corte da forragem $\times$ qualidade por estrato, obtendo-se os valores e quantidades de proteína bruta (PB), segundo Silva e Queiroz (2002).

0 delineamento experimental foi em blocos ao acaso (cinco blocos com três parcelas por bloco). As análises foram realizadas utilizando-se o procedimento GLM do SAS (2003), com nível de significância $(\mathrm{P}<0,05)$.

\section{Resultados e discussão}

São apresentados na Tabela 1 os resultados da análise de solo e da cama de frango utilizados no presente trabalho. Verificam-se os baixos níveis de fósforo $\left(5 \mathrm{mg} / \mathrm{dm}^{3}\right)$ e potássio $\left(0,8 \mathrm{mmol} / \mathrm{dm}^{3}\right)$ no solo, que foram corrigidos com a aplicação de superfosfato simples e cloreto de potássio. Em relação à cama de frango, destacam-se principalmente os teores de nitrogênio $(\mathrm{N})$ com valores de $4,27 \%$, fósforo $\left(\mathrm{P}_{2} \mathrm{O}_{5}\right)$ com 2,32\% e potássio $\left(\mathrm{K}_{2} \mathrm{O}\right)$ com $2,26 \%$.

Para a produtividade da forragem estão relacionadas, entre outros fatores, as características climáticas do local. De acordo com a Figura 1 pode-se observar que, no ano do experimento, as temperaturas mínimas encontradas foram maiores que $15{ }^{\circ} \mathrm{C}$ nos meses de outubro a maio, favorecendo o crescimento da forragem. Observa-se ainda que a precipitação encontrada foi maior de dezembro a março, sendo estes dados favoráveis para aumentar a produtividade de forragem, com valores mínimos de 5 a 6 milímetros por dia de chuva.

As produtividades de massa seca encontradas (Tabela 2) revelaram diferença significativa entre os cortes. As maiores produtividades foram encontradas nos meses de janeiro, fevereiro e março, em que as condições climáticas favoreceram o crescimento da planta (Gráfico 1). Houve diferença significativa entre os tratamentos apenas nos cortes 4 e 6, com maior produtividade quando adubados com ureia, nos demais cortes não houve diferença entre os tratamentos, evidenciando o mesmo efeito, indenpendente do fertilizante e forma de aplicação da cama de frango

Para as produtividades de folha e colmo avaliadas nos cortes 1 e 2 , constata-se que não houve diferenças significativas para os tratamentos utilizados (Tabela 3). Houve diferença somente nas proporções entres os cortes, o que era esperado em função das melhores condições climáticas (Gráfico 1). No que concerne ao material morto, houve maior valor para o tratamento com cama de frango em apenas uma aplicação, provavelmente devido ao acúmulo de forragem nos estratos inferiores da touceira.

Ainda na Tabela 3, observa-se que, para os estratos de $0,45 \mathrm{~m}$ a $1,0 \mathrm{~m}$ e para os maiores que $1,0 \mathrm{~m}, \mathrm{o}$ teor de proteína bruta e massa de folhas foram semelhantes, podendo-se inferir que a escolha entre a ureia e a cama de frango deverá estar embasada em outros critérios além da produtividade e composição proteica da forragem, como custo e facilidade na aplicação.

A fertilidade do solo, assim como a adubação, tem efeito direto na produção de forragem. A maior eficiência no uso do $\mathrm{N}$ e as respostas em termos de produção ocorrem quando os demais nutrientes

Tabela 1 - Valores referentes à análise de solo e cama de frango utilizados no experimento

\begin{tabular}{|c|c|c|c|c|c|c|c|c|c|c|c|}
\hline \multicolumn{12}{|c|}{ Análise da terra } \\
\hline $\mathrm{Ph}$ & M.O. & $\mathbf{P}_{\text {resina }}$ & $\mathbf{A l}^{3+}$ & $\mathrm{H}+\mathrm{Al}$ & K & $\mathrm{Ca}$ & $\mathrm{Mg}$ & SB & СтC & V\% & $\mathbf{S}$ \\
\hline $\mathrm{CaCl}_{2}$ & $\mathrm{~g} / \mathrm{dm}^{3}$ & $\mathrm{mg} / \mathrm{dm}^{3}$ & \multicolumn{8}{|c|}{ - } & $\mathrm{mg} / \mathrm{dm}^{3}$ \\
\hline 5,3 & 11 & 5 & 1 & 17 & 0,8 & 19 & 6 & 25 & 42 & 59 & --- \\
\hline \multicolumn{12}{|c|}{ Análise da cama de frango (\%) } \\
\hline $\mathbf{N}$ & $\mathbf{P}_{2} \mathbf{O}_{5}$ & $\mathrm{~K}_{2} \mathrm{O}$ & $\mathrm{Ca}$ & $\mathrm{Mg}$ & $\mathbf{S}$ & MS & MO & & & & \\
\hline 4,27 & 2,32 & 2,26 & 2,47 & 0,5 & 0,59 & 87 & 61 & & & & \\
\hline
\end{tabular}

Rev. Acad., Ciênc. Agrár. Ambient., Curitiba, v. 12, n. 1, p. 61-69, jan./mar. 2014 
estiverem em equilíbrio na solução do solo, gerando um ambiente favorável aos processos de absorção por parte da planta forrageira (CORSI; NUSSIO, 1993). No presente estudo, embora não tenha sido mensurado o acréscimo de nutrientes no solo provindos da cama de frango, segundo a análise exposta na Tabela 1, pode-se inferir que há contribuição não só do $\mathrm{N}$, mas também de outros nutrientes, dentre eles o fósforo e potássio, responsáveis também pela produção da forrageira.

Favoretto et al. (1988), trabalhando com capim-colonião não adubado e com adubação 50 e 100 $\mathrm{kg} /$ ha de $\mathrm{N}$, durante o verão (novembro-março), verificaram aumento na produção de massa seca, em função da elevação dos níveis de N. Ainda, outro importante fator é a estação da seca, em que as gramíneas tropicais apresentam baixa produção de forragem, obrigando os produtores a suplementarem o rebanho, elevando, assim, o custo de produção. Pinheiro (2002) observou produções médias de massa seca do capim-tanzânia de até $3.553 \mathrm{~kg} /$ ha no verão, já que no inverno o valor máximo obtido foi de $1.479 \mathrm{~kg} / \mathrm{ha}$.

Para tanto, não somente a água é limitante para o crescimento das forrageiras, mas baixas temperaturas (abaixo de $15{ }^{\circ} \mathrm{C}$ ) nas regiões tropicais são apontadas como os principais agentes causadores da estacionalidade de crescimento das plantas forrageiras tropicais (BRYAN; SHARPE, 1965). Segundo Karbassi et al. (1972), a redução do crescimento sob menores temperaturas poderia ser explicada, possivelmente, pela diminuição da atividade da amilase, retardando a hidrólise e a translocação do amido, resultando em menores teores de alimentos fixados e menor produção de massa seca de forragem.

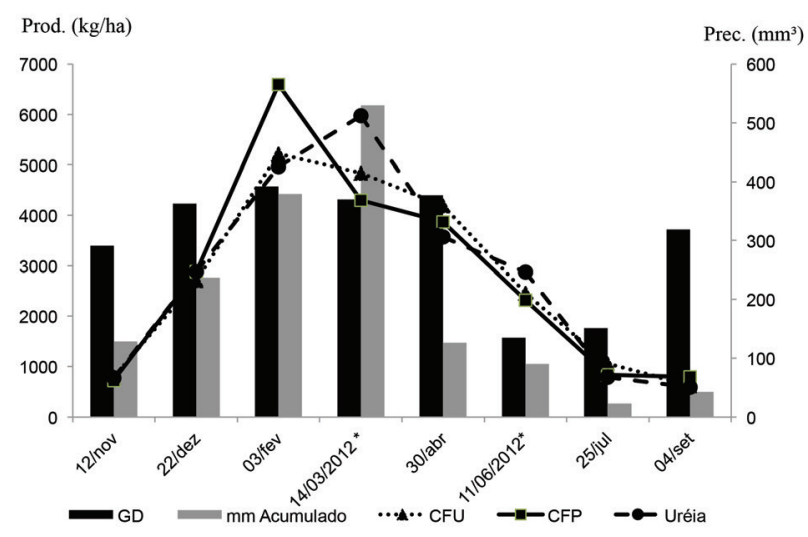

Gráfico 1 - Produtividade de massa seca $(\mathrm{kg})$ do capim-elefante, graus dia (GD), precipitação $\left(\mathrm{mm}^{3}\right)$

Legenda: * - Datas de corte para separação morfológica.

Fonte: Dados da pesquisa.

Em relação às produções de forragem encontradas, em função da adubação nitrogenada por meio da ureia e cama de frango, os valores foram semelhantes. Este resultado pode ser explicado pelo fato de que a liberação de $\mathrm{N}$ da cama foi suficiente para atender a demanda da produção forrageira, inclusive sendo superior ao tratamento referente ao parcelamento da cama em alguns casos.

Segundo Kiehl (1985), o efeito da matéria orgânica sobre a produtividade pode ser direto por meio do fornecimento de nutrientes ou pelas modificações das propriedades físicas do solo. Segundo Menezes et al. (2004), a liberação de nutrientes da cama para o solo ocorre gradativamente. Tal liberação se dá à medida que o material orgânico vai sendo mineralizado. A quantidade liberada depende do grau de mineralização, da matéria prima que deu origem ao composto e da quantidade aplicada, o que pode explicar, em função da aplicação do dobro

Tabela 2 - Produtividade de massa seca de forragem ( $\mathrm{kg} / \mathrm{ha}$ ) nos cortes e adubação com ureia ou cama de frango em dose única (CFU) ou parcelada (CFP)

\begin{tabular}{lccccccccc}
\hline \multicolumn{10}{c}{ Cortes } \\
\hline Tratamentos & $12 /$ nov & $22 / \mathrm{dez}$ & $03 / \mathrm{fev}$ & $14 / \mathrm{mar}$ & $30 / \mathrm{abr}$ & $11 / \mathrm{jun}$ & $25 /$ jul & $04 / \mathrm{set}$ & Média \\
CFU & 792 & 2704 & 5219 & $4836 \mathrm{~b}$ & 4192 & $2458 \mathrm{~b}$ & 1056 & 626 & 2735 \\
CFP & 728 & 2882 & 6597 & $4302 \mathrm{~b}$ & 3864 & $2317 \mathrm{~b}$ & 835 & 791 & 2660 \\
Ureia & 779 & 2882 & 4963 & $5969 \mathrm{a}$ & 3568 & $2872 \mathrm{a}$ & 794 & 596 & 2802 \\
Media & $766 \mathrm{D}$ & $2818 \mathrm{C}$ & $5529 \mathrm{~A}$ & $5036 \mathrm{AB}$ & $3875 \mathrm{BC}$ & $2549 \mathrm{C}$ & $895 \mathrm{D}$ & $671 \mathrm{D}$ & \\
\hline
\end{tabular}

Nota: Médias seguidas de letras minúsculas diferentes na coluna diferem entre si pelo teste de Tukey $(\mathrm{P}<0,05)$; Médias seguidas de letras maiúsculas diferentes na linha diferem entre si pelo teste de Tukey $(P<0,05)$.

Fonte: Dados da pesquisa. 
da dose recomendada por ciclo (aproximadamente $420 \mathrm{~kg}$ de $\mathrm{N}$ total por hectare por verão), a disponibilização da mesma produção quando comparada com a ureia (350 kg de $\mathrm{N}$ por verão), corroborando com os achados do presente estudo.

A cama de frango, segundo Konzen (2003), contém alta concentração de nutrientes, pois as aves têm baixos índices de aproveitamento de suas rações ( 40 a $60 \%$ apenas) e o restante é eliminado via dejetos.

Segundo Benedetti et al. (2009) e Menezes et al. (2004), a composição química da cama de frango pode modificar-se em função do material empregado para forrar os aviários e do número de lotes nos quais a cama é utilizada. No entanto, segundo estes autores, os níveis médios de Nitrogênio $(\mathrm{N})$ variam de 2 a $5 \% ; \mathrm{P}_{2} \mathrm{O}_{5}$ de 1,5 a $3 \%$ e $\mathrm{K}_{2} \mathrm{O}$ por volta de 2 a $4 \%$. Assim, basicamente, seriam estimadas as doses de aplicações levando-se em consideração os níveis almejados para as culturas utilizadas.
A utilização da cama de frango como fertilizante para forrageiras tem ainda a grande vantagem de disponibilizar nutrientes após aplicação e manter a liberação residual nos anos subsequentes. Segundo os trabalhos, no caso do nitrogênio, por exemplo, $50 \%$ são disponibilizados no primeiro ano, $20 \%$ no segundo e $30 \%$ em anos seguintes (MALAVOLTA, 1981; KIEHL, 1985).

Lima et al. (2007), estudando a influência da adubação orgânica nas propriedades químicas de um Latossolo Vermelho distrófico e sua produção de MS em pastagem de Brachiaria brizantha cv Marandu, utilizaram doses de até 20 toneladas de cama de frango/ha e outra de $100 \mathrm{~kg} / \mathrm{ha}$ de $\mathrm{N}$ na forma de ureia, encontrando aumento na produção nos tratamentos com cama de frango. Houve também diferença significativa para as variáveis: teor de $\mathrm{K}, \mathrm{P}$ e C, em relação à adubação química. Ainda, com a adubação por meio de adubo orgânico, Aréovolo (1986) verificou que, ao aplicar 20 t/ha de esterco,

Tabela 3 - Produtividade $(\mathrm{kg} / \mathrm{ha})$ de folhas, colmo e material senescente no primeiro e segundo cortes e produtividade de folhas e teor de proteína bruta no terceiro corte da forragem de capim-elefante, adubada com ureia e cama de frango em dose única (CFU) ou parcelada (CFP)

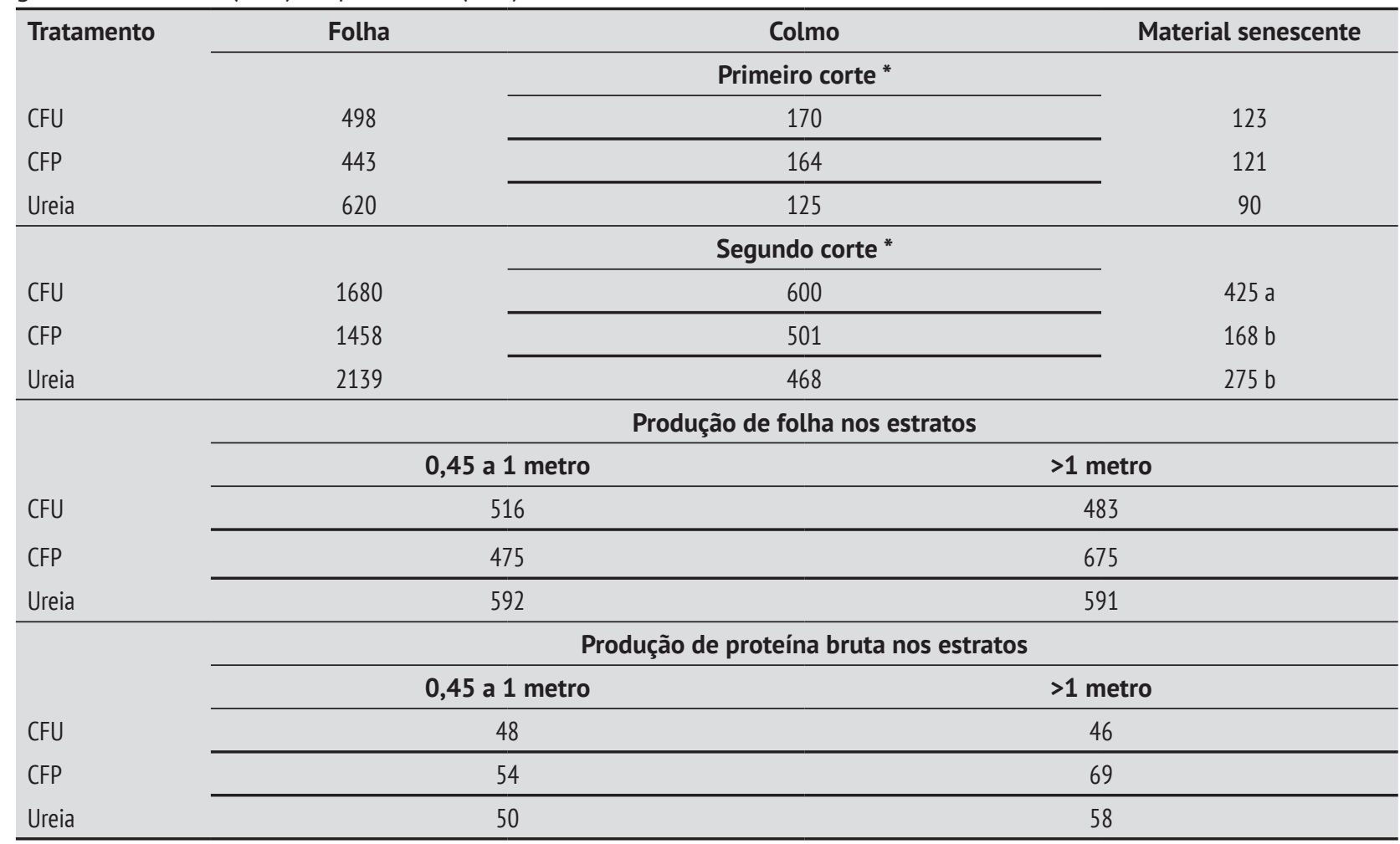

Nota: Médias seguidas de letras minúsculas distintas na coluna diferem entre si pelo teste de Tukey $(P>0,05)$. Legenda: * - Diferença estatística entre o primeiro e segundo corte da forragem pelo teste de Tukey $(p>0,05)$.

Fonte: Dados da pesquisa. 
o potássio aumentou $125 \%$ em relação à testemunha e o fósforo, também em equação quadrática, aumentou ao máximo de $20,8 \mathrm{mg} / \mathrm{dm}^{3}$, atingindo seu máximo próximo a 15 toneladas de cama de frango aplicada. Ainda, Bezerra Neto et al. (1984) encontraram resultados semelhantes ao analisar o emprego de esterco de curral em Latossolo Vermelho Amarelo.

Araújo et al. (2008), verificaram melhoria das características químicas do solo implantado com Panicum maximum cv. Mombaça, adubado com fontes de matéria orgânica. Especificamente com relação ao esterco de galinha, relataram que foi a fonte que mais contribuiu para a produção de massa da parte aérea da pastagem, sendo a única que aumentou os teores de fósforo no solo. Concluíram que este aumento pode ser explicado, neste caso, em função da matéria orgânica incorporada ao solo disponibilizando nutrientes, permitindo a absorção pelo sistema radicular com mais eficiência.

Carvalho et al. (1991) concluíram que forrageiras, como o Pennisetum purpureum Schum (capim-elefante), têm alto potencial de produção de massa seca, mas elevada taxa de remoção de nutrientes proporcionalmente. Segundo Vicente-Chandler (1974), para produção de 28,2 t/ha de MS são removidos aproximadamente $338 \mathrm{~kg}$ de N; $72 \mathrm{~kg}$ de P; $565 \mathrm{~kg}$ de potássio (K); $108 \mathrm{~kg}$ de Ca e $71 \mathrm{~kg}$ de $\mathrm{Mg}$. Portanto, em áreas com corte e retirada de forragem colhida, o potássio merece especial consideração em virtude das grandes quantidades removidas do local, pois mesmo recebendo altas quantidades de $\mathrm{N}$, as plantas que não receberam adubação potássica produziram cerca de $30 \%$ da produção máxima verificada em plantas com nível mais alto de $\mathrm{K}$. Nutrientes como Ca e Mg também são removidos do solo pela forragem.

Em relação ao capim-elefante, o incremento na produção de massa, em virtude de ser uma forrageira com alto potencial de produção, é em decorrência da aplicação de nitrogênio (CAIELLI; BONILHA NETO; LOURENÇO, 1991; ANDRADE, 1997; PACIULLO, 1997). No entanto, o aumento na produção de forragem, em resposta à adubação nitrogenada, implica também na aplicação de outros nutrientes, como potássio e fósforo, além da adoção de práticas adequadas de manejo.

Em relação às percentagens de folha, colmo e material senescente do capim em dois estratos, não houve diferenças. Para tanto, a relação lâmina/colmo é de grande importância do ponto de vista nutritivo e do manejo das espécies forrageiras. Andrade (1997), trabalhando com capim-elefante cv. Napier sob doses de nitrogênio e potássio, encontrou valor médio dessa relação na ordem de 0,80 . A composição química da forragem varia em função da idade, da parte da planta (lâmina ou colmo), da época do ano e da fertilidade do solo. Destes, destaca-se a fertilidade do solo, que pode ser manipulada por intermédio de adubação, destacando-se também o comportamento semelhante encontrado nos tratamentos com cama e ureia do presente estudo.

Em muitos trabalhos são descritos o efeito da adubação nitrogenada sobre o teor de proteína das plantas (RIBEIRO, 1995). A maioria dos trabalhos que descrevem o valor nutritivo de plantas forrageiras do gênero Pennisetum é oriunda de ensaios sobre corte em que não há interação com o animal. Além desse fato, os estudos têm por base a frequência de corte fixa relacionados com a intensidade de corte (altura do resíduo).

Ainda, em relação à estrutura da pastagem, Laca e Lemaire (2000) definem como é a distribuição espacial da biomassa aérea das plantas em uma comunidade. De forma geral, é descrita por variáveis que expressam a quantidade de forragem existente de forma bidimensional, sendo a estrutura da pastagem, a dimensão vertical e horizontal da distribuição da massa seca no perfil da pastagem, relacionando altura e densidade desta massa sobre a ingestão de forragem (BURLINSON; HODGSON; ILLIUS, 1991; TORRES-RODRIGUES et al., 1997). Tais características podem facilitar a apreensão de forragem pelos animais (STOBBS, 1973), pois a insuficiência ou a inacessibilidade de forragem pode restringir o consumo.

Ao longo do tempo a pastagem passa por fases que se caracterizam por investimentos em estruturas vegetativas ou reprodutivas, aéreas ou subterrâneas, estas relacionadas à idade ou adubação do solo para formação de folhas (CARVALHO et al., 2001), que está relacionada com o encontrado no presente estudo, sendo igual, contudo, para os tratamentos, e diferentes apenas entre cortes com épocas diferentes favorecidos por melhores fatores climáticos (verão). 
Estudos que acrescentem relações de produtividade e adubação orgânica com o uso de pastejo são importantes linhas de pesquisa, a fim de quantificar e mensurar os efeitos da adubação na produtividade, assim como na estrutura da pastagem.

\section{Conclusão}

Independente da forma de aplicação, dose única ou parcelada, a cama de frango como adubo nitrogenado substitui a ureia na adubação de cobertura do capim-elefante.

\section{Referências}

ANDRADE, A. C. Produtividade e valor nutritivo do Capim-Elefante (Pennisetum purpureum Schum. cv. Napier) sob diferentes doses de nitrogênio e potássio. 1997. 52 f. Dissertação (Mestrado em Zootecnia) Universidade Federal de Viçosa, Viçosa, 1997.

ARAÚJO, L. C. et al. Fontes de matéria orgânica como alternativa na melhoria das características químicas do solo e produtividade do capim-mombaça, Revista Acadêmica: Ciências Agrárias e Ambientais, v. 6, n. 1, p. 65-72, 2008.

ARÉVALO, E. O. R. Avaliação pelo capim-colonião do efeito de estercos e da ureia (Panicum maximum, Jacq.) aplicados em uma areia quartzosa tratada com e sem Ca (OH) $)_{2}$ 1986. 67 f. Dissertação (Mestrado em Solos e Nutrição de Plantas) - Escola Superior de Agricultura "Luiz de Queiroz", Universidade de São Paulo, Piracicaba, 1986.

BENEDETTI, M. P. et al. Utilização da cama de frango como adubo orgânico de pastagens. 2009. Beef Point. Disponível em <http://www.beefpoint.com.br/radares-tecnicos/pastagens/utilizacao-da-cama-de-frango-como-adubo-organico-de-pastagens-56121>. Acesso em: 10 mai. 2011.

BEZERRA NETO, F. et al. Níveis de máxima eficiência econômica de esterco de curral no cultivo do caupi. Pesquisa Agropecuária Brasileira, v. 19, n. 5, p. 567-571, 1984.

BRYAN, W. W.; SHARPE, J. P. The effect of urea and cutting treatments on the production of Pangola grass in southeastern Queensland. Australian Journal of Experimental Agriculture and Animal Husbandry, v. 5, n. 19, p. 433-441, 1965. doi:10.1071/EA9650433.
BURLINSON, A. J.; HODGSON, J.; ILliUS, A. W. Sward canopy structure and bite dimensions and bite weight of grazing sheep. Grass and Forage Science, v. 46, n. 1, p. 29-38, 1991. doi:10.1111/j.1365-2494.1991. tb02205.x

CARVALHO, M. M. et al. Resposta de uma espécie de braquiária à fertilização com nitrogênio e potássio em um solo ácido. Revista Brasileira de Ciência do Solo, v. 15, p. 195-200, 1991.

CARVALHO, P. C. F. et al. Pastagens altas podem limitar o consumo dos animais. In: REUNIÃO ANUAL DA SOCIEDADE BRASILEIRA DE ZOOTECNIA, 38., 2001, Piracicaba. Anais... Piracicaba: SBZ, 2001. p. 265-268.

CAIELLI, E. L.; BONILHA NETO, L. M.; LOURENÇO, A. J. Avaliação agronômica e qualitativa de pastos de capimelefante Napier (Pennisetum purpureum Schum.) fertilizados com nitrogênio ou consorciados com leguminosas tropicais para produção de carne. Boletim de Indústria Animal, v. 48, n. 1, p. 63-76, 1991.

CORSI, M.; NUSSIO, L. G. Manejo do capim-elefante: correção e adubação do solo. In: SIMPÓSIO SOBRE MANEJO DA PASTAGEM, 10., 1993, Piracicaba. Anais... Piracicaba: Fundação de Estudos Agrários Luiz de Queiroz, 1993. p. 87-116.

FAVORETTO, V.; RODRIGUES, L. R. A.; TUPINAMBÁ, L. F. Estudo do nitrogênio na produção e composição bromatológica do capim-colonião e seus aspectos econômicos. Científica, v. 16, n. 1, p. 71-78, 1988.

KARBASSI, P.; WEST, S. H.; GARRARD, L. A. Amylolytic activity in leaves of a tropical and temperate Grass. Crop Science, v. 12, n. 1, p. 58-60, 1972. doi:10.2135/cropsci1 972.0011183X001200010019x

KIEHL, E. J. Fertilizantes orgânicos. São Paulo: Agronômica Ceres, 1985.

KONZEN, E. A. Fertilização de lavoura e pastagem com dejetos de suínos e cama de aves. In: SEMINÁRIO TÉCNICO DA CUlTURA DE MILHO, 5., 2003, Videira. Anais... Videira: EMBRAPA-CNPSA, 2003, 16p. (Informe Técnico).

LACA, E. A.; LEMAIRE, G. Measuring sward structure. In: MANNETJE, L.; JONES, R. M. (Eds.) Field and laboratory methods for grassland and animal production research. Wallingford, UK: CABI Publishing, 2000. p. 103-121. 
LIMA, J. J. et al. Influência da adubação orgânica nas propriedades químicas de um Latossolo Vermelho distrófico e na produção de matéria seca de Brachiaria brizantha cv. Marandu, Acta Scientiarum Agronomy, v. 29, n. 5, p. 715-719, 2007. doi:10.4025/actasciagron.v29i5.754.

LOMBARDI NETO, F.; DRUGOWICH, M. I. Manual técnico de manejo e conservação de solo e água. Campinas: CATI, v. 2, 1994.

MALAVOLTA, E. Manual de química agrícola: adubos e adubação. São Paulo: Agronômica Ceres, 1981.

MINISTÉRIO DA AGRICULTURA, PECUÁRIA E ABASTECIMENTO - MAPA. Instrução Normativa nํ. 8, de 25 de março de 2004. Proíbe em todo o território nacional a produção, a comercialização e a utilização de produtos destinados à alimentação de ruminantes que contenham em sua composição proteínas e gorduras de origem animal. Diário Oficial [da] União, de 26 de março de 2004, Seção 1, página 5. Disponível em: <http://sistemasweb. agricultura.gov.br/sislegis/action/detalhaAto.do?metho $\mathrm{d}=$ visualizarAtoPortalMapa\&chave $=178957228>$ Acesso em: 10 mai. 2011.

MINISTÉRIO DA AGRICULTURA, PECUÁRIA E ABASTECIMENTO - MAPA. Instrução Normativa nํ. 15, de 26 de maio de 2009. Regulamentar o registro dos estabelecimentos e dos produtos destinados à alimentação animal. Diário Oficial [da] União, de 28 de maio de 2009, Seção 1. Disponível em: <http://sistemasweb.agricultura.gov.br/sislegis/action/detalhaAto.do?method=visuali zarAtoPortalMapa\&chave $=2113570100>$. Acesso em: 10 mai. 2011.

MENEZES J. F. S. et al. Cama de frango na agricultura: perspectivas e viabilidade técnica e econômica. Rio Verde: FESURV, 2004. 28 p. (Boletim Técnico, 3).

MORAES, B. E. R. et al. Potencialidades do uso de cama de frango na recuperação de pastagens degradas de Brachiaria decumbens. Veterinária Notícias, v. 12, n. 2, p. $127,2006$.

PACIULLO, D. S. C. Produtividade e valor nutritivo do capim-elefante Anão (Pennisetum purpureum Schum cv. MOTT) ao atingir 80 e 120 cm de altura sob diferentes doses de nitrogênio. 1997. 60 f. Dissertação (Mestrado em Zootecnia) - Universidade Federal de Viçosa, Viçosa, 1997.
PINHEIRO, V. D. Viabilidade econômica da irrigação de pastagem de capim Tanzânia em diferentes regiões do Brasil. 2002. 85 f. Dissertação (Mestrado em Agronomia) - Escola Superior de Agricultura "Luiz de Queiroz", Universidade de São Paulo, São Paulo, 2002.

RIBEIRO, K. G. Rendimento forrageiro e valor nutritivo do capim-elefante "Anão", sob cinco doses de nitrogênio, ao atingir 80 e 120 cm de altura. 1995. 60 f. Dissertação (Mestrado em Zootecnia) - Universidade Federal de Viçosa, Viçosa, 1995.

STATISTICAL ANALYSIS SYSTEM - SAS. SAS: user's guide for windows environment. Version 8. Cary, NC: SAS Institute Inc., 2003.

SILVA, D. J.; QUEIROZ, A. C. Análise de alimentos: métodos químicos biológicos. 2. ed. Belo Horizonte: Fundação de Ensino e Pesquisa em Medicina Veterinária, 2002.

STOBBS, T. H. The effect of plant structure on the intake of tropical pastures. II. Differences in sward structure, nutritive value, and bite size of animals grazing Setaria anceps and Chloris gayana at various stages of growth. Australian Journal of Agricultural Research, v. 24, n. 6, p. 821-829, 1973. doi:10.1071/AR9730821.

TORRES-RODRIGUEZ, A. et al. Cattle diet preference and species selection as influenced by availability. Proceedings of the New Zealand Society of Animal Production, v. 57, p. 197-198, 1997.

VICENTE-CHANDLER, J. Fertilization of humid tropical grasslands. In: MAYS, D. A. Forage fertilization. Madison: American Society of Agronomy, 1974. p. 277-300.

Recebido: 28/02/2013

Received: 02/28/2013

Aprovado: $13 / 03 / 2014$

Approved: 03/13/2014 